\title{
Report on the First Probiotics Summit 2015 (PBS-2015)
}

\author{
Dilek Heperkan \\ Department of Food Engineering, Istanbul Technical University, Turkey
}

Correspondence to:

Prof. Dilek Heperkan

Istanbul Technical University

Chemical and Metallurgical Engineering Faculty

Department of Food Engineering, Turkey

E-mail: heperkan@itu.edu.tr

Received: September 30, 2015

Accepted: October 06, 2015

Published: October 08, 2015

Citation: Heperkan D. 2015. Report on the First Probiotics Summit 2015 (PBS-2015). J Food Chem Nanotechnol 1(1): 13-14.

Copyright: (c) 2015 Heperkan. This is an Open Access article distributed under the terms of the Creative Commons Attribution 4.0 International License (CC-BY) (http://creativecommons. org/licenses/by/4.0/) which permits commercial use, including reproduction, adaptation, and distribution of the article provided the original author and source are credited.

Published by United Scientific Group

\section{Meeting Report}

Probiotics Summit 2015 (PBS-2015) concluded successfully on July 08, 2015. The three day summit was organized by United Scientific Group (USG) during July 06-08, 2015 at DoubleTree By Hilton, San Francisco, USA. PBS2015 was themed around "Healthy Bacteria for Healthier Life".

PBS-2015 featured many highly informative and interactive sessions to encourage the exchange of ideas across a broad range of disciplines in Probiotic Industry. The meeting witnessed exclusive discussions on latest trends in Probiotics bacteria and its applications in food industry, outbreaks in healthy food products development and initiatives to improve the health conditions free from infectious diseases.

The PBS-2015 gathered academicians, industrialists and young researchers from twenty different countries around the globe for open networking and sharing of recent work in Probiotics.

\section{Probiotics Summit Rendered Presentations on:}

Inventions in probiotics and prebiotics, Probiotics in veterinary science, Dairy technology, Role of probiotics in infectious diseases, Novel probioceuticals, Microbiology \& Immunology, Probiotics in oral health and dentistry, Probiotics in pediatrics, Probiotics in functional foods, Advancements in probiotics, prebiotics and nutraceutics, Aquaculture, Study of intestinal interactions, Animal physiology and animal nutrition, Nutritional science \& nutraceuticals, Probiotics guidelines in weight loss, Gastrointestinal system, Industrial probiotics, Inflammatory bowel disease \& crohn's disease, Probiotics in women's health, Benefits of probiotics supplements.

\section{PBS-2015 Pre-conference Workshops}

USG in association with Istanbul Technical University (ITU) successfully organized "Istanbul Probiotics Workshop 2015" on March 19, 2015 at ITU, Turkey. USG also associated with The Stephan Angeloff Institute of Microbiology and Bulgarian Academy of sciences and successfully organized "Beneficial and pathogenic microbes for healthier life and safety foods" workshop on April 8-9, 2015 at Institute of Microbiology, Sofia, Bulgaria. We would like to extend our sincere thanks to Dr. Dilek Heperkan, Istanbul Technical University, Turkey and Dr. Svetla T. Danova, The Stephan Angeloff Institute of Microbiology, Bulgaria for their dedicated support and contribution.

The pre-conference workshops are aimed to explore critical points in probiotics-beneficial microbes by providing an opportunity to the participants and young researchers to discuss various issues pertaining to their research career. 


\section{PBS-2015 Conference Report}

In the beautiful bay area of San Francisco, the day 1 (July 06,2015) started with the Dr. Laurel Lagenaur keynote speech on "Development of a live biotherapeutic product as a vaginally disintegrating tablet to prevent HIV infection". Dr. Lagenaur during her keynote, presented the idea of using bioengineered vaginal lactobacilli to reduce the changes of HIV infection through vaginal intercourse. Dr. Afaf El-Ansary from Saudi Arabia delivered the second keynote of Day 1 on "Role of microbiota-gut-brain axis in mental health with the emphasize of autoantibodies: effect of probiotics and nutritional interactions". Dr. Ansary's talk presented a strong link between gut micro biodata and brain health which opens a new promising strategy for brain-related disorders. After the keynotes, the session continued with the speaker presentations on various topics including food, dairy, gut microbe and beneficial bacteria.

Day 2(July 07,2015) opened with the keynote presentation by Dr. Mun Yhung Jung on "Highly efficient extraction method for gas chromatographic analysis of conjugated linoleic acid (CLA) from probiotic bacteria grown MRM medium: A rapid screening tool for the probiotic bacteria having CLA producing activity". The presentation discussed about the efficient analytical method for probiotic bacteria having high CLA producing activity. PBS-2015 also had some noteworthy oral and poster presentation on Day 2. After the series of speaker session and poster presentations, the day ended with grand reception. The speaker presentations continued till the lunch hour of Day 3 and PBS-2015 finally concluded with the closing ceremony and certificate distribution.

USG is obliged to the committee members of PBS-2015, our associated organization Paidoss and collaborators Istanbul technical university, Bulgarian Academy of science's for their outstanding support and participation. 